УДК 616.665-002.28

DOI: 10.26435/UC.V0I3(36).609

\author{
А.Г. Кривобок, Ю.Ю. Малинин, С.Г. Ермилов, Г.И. Ермилов
}

ГОО ВПО «Донецкий национальный медицинский университет имени М. Горького», Донецк

\title{
СОВРЕМЕННОЕ ПОНИМАНИЕ ПРОБЛЕМЫ БОЛЕЗНИ ПЕЙРОНИ
}

Болезнь Peyronie's, или фибропластическая индурация полового члена (от латинского induracio penis plastika - IPP) - достаточно редкое заболевание, в основе которого лежит локальное повреждение белочной оболочки (tunica albuginea) кавернозных тел полового члена [1].

Фибропластическая очаговая индурация полового органа мужчины была известна на протяжении многих веков эскулапам древнего мира. Типичное S-образное искривление полового члена увековечено в скульптурах времен Римской империи, хранящихся в Британском Национальном музее.

Первые детальные описания идиопатической фибропластической индурации полового члена были сделаны основателем современной анатомии Andreas Vesalius (1514-1564) в его книгах «Tabula Anatomicae Sex» (1538) и «De Humani Corporis Fabrica» (1543). Позже, другой известный анатом, Габриэль Fallopius (1523-1562) в своем трактате «Observationes Anatomicae» (1561) также обсуждал эту патологию. Однако, болезнь была систематизирована и детально описана главным хирургом Короля Луи XV и основателем Парижской Хирургической Академии François Gigot de la Peyronie в 1743 году в статье «Some obstacles opposing the natural ejaculation of semen». В ней автор приводит описания трех пациентов с болезненным отвердением и искривлением полового члена во время полового акта [2].

Пейрони лечил пациентов минеральной водой Barèges и ртутными растираниями. Некоторым такое лечение даже помогало. Пейрони не был первым человеком, описавшим эту болезнь. В 1687 году, аналогичное патологическое состояние было описано Эфемеридесом, но именно Пейрони привел более подробные данные и расценил его как болезнь, сформулировал особенности развития и предпринял первые попытки лечения [2].

Авторитет, завоеванный в операционных и анатомических театрах, не позволил забыть имя французского врача. Именно поэтому, термин «болезнь Пейрони», является в настоящее время общепринятым для обозначения фиброзного поражения белочной оболочки кавернозных тел. Фибропластическая индурация полового члена известна и как «болезнь Buren's» по фамилии одного из авторов Van Buren и Keyes, которые повторно описали это заболевание в конце XIXого столетия. Другие, менее известные названия этой деформации, такие как «coles incurvatus», «penis lunatus», «induratio penis plastica», а также «bent spike syndrome» не получили распространения в литературе.

Несмотря на почти трёхсотлетний период изучения болезни Пейрони, проблема этиологии, патогенеза и лечения этой болезни и на сегодня остается актуальной и нерешенной. Известный французский хирург W.D. Dunsmuir (2003) пишет: «Несмотря на огромное число методов лечения болезни Пейрони, идеального способа не существует. Болезнь Пейрони остается нерешенной проблемой. Причины заболевания неясны, лечение сложно» [3].

Болезнь Пейрони в настоящее время относят к группе хронических неэпидемических неинфекционных заболеваний. Эпидемиологические показатели распространенности заболевания в мужской популяции колеблются в широком диапазоне - от 0,4\% до 3,2\% [4]. Однако, ряд исследователей приводят цифры от 1-2\% до 3\% и даже $7,1 \%$ [5, 6]. Предполагается, что показатели намного превышают существующие статистические данные о распространённости болезни Пейрони. По результатам последних эпидемиологических исследований, заболеваемость оценивается разными авторами от 3,7\% до $8,9 \%$, что значительно выше, чем считалось ранее [7, 8].

Болеют мужчин различных возрастных групп. Две трети пациентов заболевают в возрасте от 40 до 60 лет, то есть, в период максимальной социальной и половой активности [9]. Хотя описан случай болезни Пейрони у пациента 18 лет [10].

\footnotetext{
(c) А.Г. Кривобок, Ю.Ю. Малинин, С.Г. Ермилов,

Г.И. Ермилов, 2020
}

(c) Университетская Клиника, 2020 
Есть также косвенное свидетельство о том, что реальная распространенность болезни Пейрони намного шире - в одной из своих работ, B.H.Smith (1969) указывает, что при аутопсии обнаружил фиброзные бляшки в кавернозных телах у 23 из 100 трупов [11]. По данным D.Ralph и J.Pryor (2002), первичная заболеваемость недугом увеличивается от 3-4 случаев заболевания на 100000 мужчин в возрасте 20-29 лет до 66 на 100000 мужчин 50-59 лет [12].

Для исследования истинной распространенности болезни Пейрони, использовали анкетирование мужчин во время скрининга по поводу рака простаты. По данным проведенного исследования, болезнь Пейрони распространена среди 8,9 \% мужчин [13]. У этих пациентов статистически достоверно чаще встречались курение, злоупотребление алкоголем, сахарный диабет, артериальная гипертензия и рак простаты [14].

Среди причин низкой обращаемости пациентов, следует отметить нежелание рассказывать об искривлении полового члена при эрекции и подвергаться врачебному осмотру. Поэтому, главной причиной обращения к специалисту является наличие болезненной эрекции, а этот симптом отмечается при болезни Пейрони далеко не всегда [15].

При анализе тенденций эпидемиологии болезни Пейрони, следует отметить склонность к увеличению первичной заболеваемости и распространенности. Причиной этого является как увеличение сексуальной активности мужчин средних лет, так и повышение уровня информированности пациентов. Необходимо отметить, что в отличие от многих других заболеваний, обращение пациента к андрологу редко происходит на ранней стадии. Мужчина либо долгое время не замечает симптомов болезни, либо стесняется обращаться к врачу [16].

Этиология болезни Пейрони в настоящий момент изучена не до конца и до настоящего времени является предметом дискуссии $[7,17]$. Всегда существовало несколько концепций развития этого заболевания. В эпоху схоластической медицины, болезнь Пейрони считалась Божьей карой за различные сексуальные девиации: инцест, гомосексуализм. Впрочем, некоторые теологи утверждали, что причиной развития фиброзной индурации полового члена может быть даже супружеская неверность.

По мере развития фундаментальных наук в $\mathrm{XX}$ веке стали возникать новые концепции этиологии заболевания. Причиной развития болезни Пейрони считалось неспецифическое воспаление уретры с образованием периваскулярных инфильтратов [11]. Была выявлена статистически достоверная связь между развитием болез- ни Пейрони и предшествующими диагностическими обследованиями, во время которых могло произойти инфицирование уретры при манипуляциях [18]. В дальнейшем доказали, что причиной воспалительного инфильтрата, возникающего на начальных стадиях заболевания, является микротравма полового члена [1].

Деформация пениса может быть как врожденной, так и приобретенной. Наличие деформации определяется состоянием тканей. Врожденное искривление полового члена характеризуется низким показателем эластичности тканей, то есть, речь идет о недоразвитости тканей. Приобретенная деформация сопровождается локальным фиброзом [19].

Наибольшее распространение получила теория возникновения заболевания в результате хронической травмы кавернозных тел во время полового акта. На протяжении многих десятилетий, было принято считать травму (нередко - субклиническую) полового члена, как наиболее вероятную причину начала болезни Пейрони [20]. Существует также аутоимунная теория развития процесса. Травма стимулирует аутоимунную реакцию, приводящую к замещению фиброзной тканью здоровых участков белочной оболочки кавернозных тел и, как следствие - образованию «бляшек Пейрони» [21].

По мнению авторов, травма приводит к отложению фибрина, что, являясь пусковым механизмом воспаления, привлекает макрофаги и нейтрофилы, что, в свою очередь, активизирует фибробласты с последующей клеточной пролиферацией, повышением сосудистой проницаемости, стимуляцией хемотаксических факторов воспалительных клеток (гистиоцитов). Возникает процесс воспаления, индурации и накопления фибрина между слоями белочной оболочки [22]. Уникальная анатомия белочной оболочки, которая состоит из двух слоев плотной и слабо васкуляризированной соединительной ткани [23], является «ловушкой» для воспалительной реакции - процесс затягивается на месяцы и годы. Время, в течение которого образуется рубцовая ткань, длится примерно 1-1,5 года, приводя к дистрофии коллагеновой ткани и матриксных основ оболочки вследствие избыточной активности фибробластов [24].

Наиболее вероятно, что у болезни нет единого этиологического фактора, а многочисленные причины могут вызывать развитие бляшек. Однако, патологические изменения однотипны во всех случаях. Установлено, что периваскулярная активация клеток может сопровождаться развитием волокнистой соединительнотканной бляшки с последующей метаплазией в хрящевую и костную ткани $[25,26]$. 
При болезни Пейрони, формирование единичных или множественных фиброзных бляшек начинается как асептическое воспаление в соединительной ткани между белочной оболочкой кавернозных тел и их эректильной тканью. Привлекая к воспалительному процессу эластическую ткань белочной оболочки и не затрагивая собственную фасцию полового члена и эректильную ткань, заболевание проходит четыре стадии развития: латентную, манифестную, стадию стабилизации и конечную стадию $[15,27]$.

В качестве этиологических факторов рассматривались: травма полового члена (включая и микротравму), нарушение эндокринного равновесия в системе гипофиз-кора надпочечников, болезни соединительной ткани с различными вариациями воспалительно-аллергического процесса и различной локализацией патологического процесса, аутоиммунные реакции, генетическая предрасположенность, образование свободных радикалов, дефицит витамина Е, инфекции, применение $\beta$-блокаторов [28]. Последние исследования представляют болезнь Пейрони, как локализованное нарушение процесса заживления в соединительной ткани [29], а гиперпродукцию фактора TGF-1 $\beta$, как возможный патогенетический механизм данного заболевания [7].

Большое значение в развитии болезни Пейрони имеет трансформирующий фактор роста $\beta$ (TGF- $\beta 1)$. Он является хемоаттрактантом для моноцитов, индуцирует ангиогенез и регулирует выработку других медиаторов воспаления; стимулирует синтез межклеточного вещества, ингибируя протеазы, что ведет к интенсивному фиброзу. Увеличение экспрессии этого фактора отмечается при любом повреждении белочной оболочки полового члена, даже при ее биопсии. Это подтверждено опытами на животных. Доказано, что TGF- $\beta 1$ присутствует в достоверно высоких концентрациях в очагах болезни Пейрони, кроме того, он обладает способностью стимулировать собственный синтез [30, 31].

Значительную роль в патогенезе болезни Пейрони играет фактор роста фибробластов (PDGF). В области формирующейся бляшки активно функционируют фибробласты, в этих участках отмечено значительное повышение концентрации PDGF [28].

Большое значение для развития болезни Пейрони имеет NO-синтаза. Известно, что от уровня концентрации этого фермента зависит степень повреждения клеток при воспалении. Поэтому многие ученые считают, что вещества, потенциально способные ингибировать NO-синтазу, могут быть эффективны в лечении данного заболевания [32].
Большое влияние на развитие болезни Пейрони оказывают генетические нарушения. Обычно фибробласт под воздействием TGF- $\beta 1$ и PDGF превращается в миофибробласт. После активации эти клетки начинают синтез коллагена, который прекращается с естественной гибелью миофибробластов вследствие генетически обусловленного апоптоза. При болезни Пейрони миофибробласт функционирует намного дольше. Все гены, регулирующие процессы образования фиброзной ткани, могут быть разделены на группы в зависимости от функции: стимулирующие фиброз, контролирующие пролиферацию, дифференцировку и апоптоз фибробластов. В свою очередь, в этих группах выделяют гены, отвечающие за синтез коллагена, активирующие синтез TGF- $\beta 1$, влияющие на активацию ангиотензиновой системы, апоптоз фибробластов, метаболизм коллагена и эластина, отложение кальция в бляшке.

Таким образом, для каждой стадии болезни Пейрони определены регулирующие гены, и сделано предположение о том, что весь патогенез обусловлен нарушением экспрессии этих генов [33]. Авторы продолжают исследования, направленные на создание генной терапии заболевания.

В развитии болезни Пейрони значительную роль играет токсическое воздействие продуктов перекисного окисления липидов и свободных радикалов. Активные кислородные соединения относятся к классу свободных радикалов и образуются из кислорода в присутствии прооксидантных факторов. Наиболее значимыми свободными радикалами являются супероксиданион, перекись водорода, гидроксильный и пероксильный радикалы и пероксинитрит-анион. Супероксид-анион образуется в моноцитах, нейтрофилах, лимфоцитах в сложном каскаде с участием никотинамидадениндинуклеотидфосфата (НАДФ). Перекись водорода образуется из кислорода с участием супероксиддисмутазы, соединение достаточно стабильное, но при взаимодействии с внутриклеточным железом, образует гидроксильный радикал. Он является наиболее токсичным среди активных кислородных соединений. Оксид азота (NO) принимает участие в расслаблении гладких мышц, однако при этом требуется присутствие многих кофакторов. При дисбалансе последних и в присутствии супероксид-иона образуется пероксинитрит, который принимает активное участие в перекисном окислении липидов. Данный процесс разрушает клеточные структуры; для того чтобы блокировать перекисное окисление липидов в клетке, существует развитая антиоксидантная система, включающая супероксиддис- 
мутазу, каталазу, глутатионпероксидазу, глутатионредуктазу. Существуют также и внеклеточные антиоксиданты: витамины С, Е, аминобензойная кислота, билирубин. Некоторые из них располагаются на мембранах клеток: селен, каротиноиды, витамин Е [32].

При болезни Пейрони, в белочной оболочке развивается хронический воспалительный процесс, сопровождающийся массивной клеточной инфильтрацией. При этом, иммунокомпетентные клетки вырабатывают большое количество активных кислородных соединений. Для противодействия им, активность антиоксидантной системы также повышается, но этого недостаточно, чтобы предотвратить разрушение клеточных структур. Таким образом, в очаге воспаления при болезни Пейрони происходит достоверное увеличение концентрации свободных радикалов, что способствует дополнительному повреждению клеток. Доказано, что дисрегуляция TGF- $\beta 1$ во многом обусловлена именно оксидативным стрессом. Последний, нарушает также внутриклеточный баланс ядерного фактора kарра B, влияющего на процессы восстановления тканей $[31,34]$.

Помимо углубления знаний о патогенезе болезни Пейрони, гистохимические исследования дают научное обоснование применению антиоксидантов (в том числе витамина Е) при консервативной терапии [4]. Таким образом, при проведении консервативной терапии болезни Пейрони, использование антиоксидантов в острой фазе заболевания становится оправданным. Существуют возможности применения витаминов С, Е, каротиноидов, селена, убиквинонов. По мнению ведущих ученых, занимающихся изучением гистохимических особенностей болезни Пейрони, дальнейшие исследования должны быть направлены на изучение роли оксидативного стресса в формировании бляшек и их кальцификации и разработку способов воспрепятствовать этому [4, 14, 26].

Проведенные исследования свидетельствуют об ассоциации болезни Пейрони с такими генетически обусловленными заболеваниями соединительной ткани, как контрактура Дюпюитрена, тимпаносклероз, ретроперитонеальный фиброз $[16,17]$. Исследователи установили связь болезни Пейрони с антигенами главного комплекса гистосовместимости HLA-B27. В целом, можно выделить два пути, по которым возможен иммуногенетический вариант развития заболевания: молекулярная мимикрия инфекционных агентов с последующим запуском аутоиммунного ответа и спонтанный запуск через презентацию генов HLA [30].
Экспрессия генов при болезни Пейрони исследована и представлена во многих фундаментальных работах [35]. Выделяются следующие группы генов: профиброзные; гены, контролирующие пролиферацию фибробластов; антифиброзные. Углубленное исследование экспрессии различных генов на разных стадиях болезни Пейрони, позволило подтвердить гипотезу о большом значении генетической предрасположенности в развитии заболевания, а также наметить пути для изучения возможностей генетической терапии [30].

Гипотеза об аутоиммунной природе заболевания была высказана еще более 40 лет назад, и на сегодняшний день появляется все больше и больше данных, подтверждающих ее [36].

Поскольку болезнь Пейрони часто сочетается с контрактурой Дюпюитрена, узловым склерозом ушных раковин, периартритом плеча и лопатки (болезнь Дюпле), склеродермией и дерматомиозитом, а также другими локальными формами фиброматозов (коллагенозов), то это позволяет предположить генез заболевания, как локальное проявление системного коллагеноза [37].

Имеется мнение о том, что формирование бляшек при болезни Пейрони - процесс, который имеет мультифакторную этиологию и включает цепь генетических, структурных и иммунологических звеньев, действительные причины которых окончательно не выяснены [38].

Заболевание начинается с появления в белочной оболочке кавернозных тел инфильтрата, который, как правило, не имеет четких границ. В дальнейшем в данной зоне образуется участок фиброза, иногда с последующей инкрустацией солями кальция. Поскольку при эрекции растяжимость белочной оболочки в зоне бляшки ограничена, возникает различной степени искривление полового члена (эректильная деформация). Как правило, процесс формирования бляшки заканчивается через 12-18 мес. и наступает стабилизация заболевания. Вовлечение в процесс прободающих сосудов и дорсальных артерий полового члена приводит к нарушению механизма закрытия вен и артериальной недостаточности полового члена [39].

Основными морфогенетическими механизмами вовлечения кавернозных тел полового члена при болезни Пейрони, являются: атрофия сосудистых каверн и периваскулярных гладкомышечных волокон с уменшением необходимого объема сосудов синусоидного типа, дисплазия соединительной и сосудистой тканей, фибромускулярная, нодулярная и продольная гиперплазия гладкомышечных волокон. Сочетание нодулярной и/или диффузной соединитель- 
нотканной, мышечной и сосудистой дисплазий с очагами ангиоматоза, нарушением кровотока свидетельствуют об общности морфогенетических механизмов, которые развиваются в белочной и эректильной тканях при болезни Пейрони [39].

Описанные морфологические изменения могут служить структурной основой для разработки новых методов терапевтического и хирургического лечения пациентов с фибропластическая индурацией полового члена.

\section{ЗАК ЛЮЧЕНИЕ}

Анализ представленных литературных данных показывает, что болезнь Пейрони является часто встречающимся и малоизученным прогрессирующим заболеванием полового члена, и на сегодняшний день эта проблема так и остается нерешенной. Заболевание влечет за собой необратимые последствия, поэтому очень важно заподозрить болезнь Пейрони на ранних стадиях и начать своевременное лечение.

\section{А.Г. Кривобок, Ю.Ю. Малинин, С.Г. Ермилов, Г.И. Ермилов}

ГОО ВПО «Донецкий национальный медицинский университет имени М. Горького», Донецк

\section{СОВРЕМЕННОЕ ПОНИМАНИЕ ПРОБЛЕМЫ БОЛЕЗНИ ПЕЙРОНИ}

Болезнь Пейрони является неизученным до конца прогрессирующим заболеванием, что представляет собой одну из актуальных проблем современной урологии-андрологии. Это состояние может повлечь за собой возникновение эректильной дисфункции у мужчин фертильного возраста, а его негативное влияние на копулятивную функцию крайне неблагопри- ятно сказывается на качестве жизни пациентов. Данный литературный обзор посвящен эпидемиологии, патофизиологии болезни Пейрони

Ключевые слова: болезнь Пейрони; половой член; фибропластическая индурация; фиброзная бляшка; белочная оболочка.

\section{A.G. Krivobok, Yu.Yu. Malinin, S.G. Ermilov, G.I. Ermilov \\ SEI HPE «M. Gorky Donetsk National Medical University», Donetsk}

\section{MODERN UNDERSTANDING OF PEYRONIE'S DISEASE}

Peyronie's disease remains an understudied progressing disease being one of the relevant problems of modern urology and andrology. This condition may cause erectile dysfunction in men of fertile age and its negative impact on sexual function adversely affects patients' quality of life. This article reviews epidemiology, pathophysiology of Peyronie's disease.

Key words: Peyronie's disease; penis; fibroplastic induration; fibrous plaque; tunica albuginea.

\section{ЛИТЕРАТУРА}

1. Касенова Б.Ж, Нотов И.К., Борвин Е.А., Еркович А.А. Современные представления о патогенезе и методах лечения болезни Пейрони. Здравоохранение Югры: опыт и инновации. 2018; 4: 57-65.

2. Малей М. Франсуа Пейрони - лейб-медик короля, заложивший фундамент будущего урологии. Мед. аспекты здоровья мужчин. 2014; 4: 61-63.

3. Dunsmuir W.D. Francois de la Peyronie the man, his life, and the disease. European Urology Today. 2003; 4: 3.

4. Hauptmann A., Diemer T., Weidner W. Peyronie's disease: diagnostics and therapy. Urologe. 2011; 50 (5): 609-620.

5. Иванченко Л.П. Диагностика и лечение острой стадии болезни Пейрони: автореферат дисс. канд. мед. наук. Москва; 2007. 22.

6. Kuehhas F.E., Weibl P., Georgi T., Djakovic N., Herwig R. Peyronie's Disease: Nonsurgical Therapy Options. Rev. Urol. 2011; 13 (3): 139-146.

7. Levine L.A., Newell M., Taylor F.L. Penile traction therapy for treatment of Peyronie`s disease: a single-center pilot

\section{REFERENCES}

1. Kasenova B.Zh, Notov I.K., Borvin E.A., Erkovich A.A. Sovremennye predstavlenija o patogeneze i metodah lechenija bolezni Pejroni. Zdravoohranenie Jugry: opyt i innovacii. 2018; 4: 57-65. (in Russian).

2. Malej M. Fransua Pejroni - lejb-medik korolja, zalozhivshij fundament budushhego urologii. Med. aspekty zdorov'ja muzhchin. 2014; 4: 61-63.

3. Dunsmuir W.D. Francois de la Peyronie the man, his life, and the disease. European Urology Today. 2003; 4: 3. (in Russian).

4. Hauptmann A., Diemer T., Weidner W. Peyronie's disease: diagnostics and therapy. Urologe. 2011; 50 (5): 609-620.

5. Ivanchenko L.P. Diagnostika i lechenie ostroj stadii bolezni Pejroni: avtoreferat diss. kand. med. nauk. Moskva; 2007. 22. (in Russian).

6. Kuehhas F.E., Weibl P., Georgi T., Djakovic N., Herwig R. Peyronie's Disease: Nonsurgical Therapy Options. Rev. Urol. 2011; 13 (3): 139-146.

7. Levine L.A., Newell M., Taylor F.L. Penile traction therapy 
study. J. Sex. Med. 2008; 5: 1468-1473.

8. Levine LA. Partial plaque excision and grafting (PEG) for Peyronie's disease. J. Sex. Med. 2011; 8 (7): 1842-5.

9. Карагужин С.К. Современный подход к лечению фибропластической индурации полового члена: автореферат дисс. док. мед. Наук. Москва; 2010. 36.

10. Tal R., Hall M.S., Alex B., Choi J., Mulhall J.P. Peyronie's disease in teenagers. J. Sex. Med. 2012; 9 (1): 302-8.

11. Smith B.H. Subclinical Peyronie's disease. Am. J. Clin. Pathol. 1969; 52 (4): 385-90.

12. Pryor J., Ralph D. Clinical presentation of Peyronies disease. Int. J .Impotence Res. 2002; 14: 414-417.

13. Mulhall J.P. Subjective and objective analysis of the prevalence of Peyronie's disease in a population of men presenting for prostate cancer screening. J. Urol. 2004; 171 (1): 2350-3.

14. Hellstrom W.J., Feldman R.A., Coyne K.S., Kaufman G.J. Self-report and Clinical Response to Peyronie's Disease Treatment: Peyronie's Disease Ouestionnaire Results From 2 Large Double-Blind, Randomized, Placebo-Controlled Phase 3 Studies. Urology. 2015; 86 (2): 291-98.

15. Гурженко Ю.Н. Фибропластическая индурация полового члена. Киев; 2004. 382

16. Болезнь Пейрони. Под ред. проф. П.А. Щеплева. М.: ИД «АБВ-пресс»; 2012. 216.

17. Москалева, Ю.С., Остапченко А.Ю., Корнеев И.А. Болезнь Пейрони. Урологические ведомости. 2015; 4 : 30-35.

18. Chilton C.P. Factors associated in the aetiology of Peyronie's disease. Br. J. Urol. 1982; 54 (6): 748-50.

19. Шамраєв С.М., Возіанов С.О., Горпінчеко I.I., Бабюк I.O., Нагорний O.Є. Хірургічне лікування девіаций статевого органу із засьосуванням біодеградуючого колагену. Здоровье мужчины. 2009; 4: 23-26.

20. Таруашвили И.Г., Породенко Е.А., Таруашвили Г.И., Симоненко Е.В. Результаты обследования пациентов и болезнью Пейрони III-IV стадией. Кубан. науч. мед. вестн. 2005; 5-6: 115-119.

21. Costa W.S., Rebello S.B., Cardoso L.E., Cavalcanti A.G., Sampaio F.J. Stereological and biochemical analysis of muscular and connective tissue components in the penile corpus cavernosum adjacent to the fibrous plaque of Peyronie's disease. BJU Int. 2009; 103 (2): 212-6.

22. Paulis G, Brancato $T$. Inflammatory mechanisms and oxidative stress in Peyronie's disease: therapeutic «rationale» and related emerging treatment strategies. Inflamm Allergy Drug Targets. 2012; 11 (1): 48-57.

23. Anafarta K., Beduk Y., Uluoglu O., Aydos K., Baltaci S. The significance of histopathological changes of the normal tunica albuginea in Peyronie's disease. Int.Urol. Nephrol. 1994; 26: 71-77.

24. Brock G., Hsu G. The anatomy of the tunica albuginea in the normal penis and in Peyronies disease. J. Urol. (Baltimore). 1997; 157: 276-281.

25. Gelbard M.K. Dystrophic Penile calcification in Peyronie's disease. J. Urol. 1997; 157 (1): 316-319.

26. Cortés-González J.R., Glina S. Conservative treatment of Peyronie's disease: colchicine vs. colchicine plus vitamin E. Actas. Urol. Esp. 2010; 34 (5): 444-9.

27. Неймарк Б.А., Бесклубова Е.В. Исследование микроциркуляции в тканях полового члена с помощью лазерной допплеровской флоуметрии при болезни Пейрони. Казанский медицинский журнал. 2011; 92 (4): 513-516.

28. Bekos A., Arvaniti M., Hatzimouratidis K., et al. The natural history of Peyronie`s disease: an ultrasonographybased study. J. Urol. 2008; 53 (3): 644-650.

29. Kovac J.R., Brock G.B. Surgical outcomes and patient satisfaction after dermal, pericardial, and small intestinal submucosal grafting for Peyronie`s disease. J. Sex. Med. 2007; 4: 1500-1508.

30. Ralph D.J., Schwartz G., Moore W., Pryor J.P., Ebringer A., Bottazzo G.F. The genetic and bacteriological aspects of Peyronie's disease. J. Urol. 1997; 157 (1): 291-4.

31. El-Sakka A.I., Salabas E., Dinçer M., et al. The pathophysiology of Peyronie's disease. Arab Journal of for treatment of Peyronie`s disease: a single-center pilot study. J. Sex. Med. 2008; 5: 1468-1473.

8. Levine LA. Partial plaque excision and grafting (PEG) for Peyronie's disease. J. Sex. Med. 2011; 8 (7): 1842-5.

9. Karaguzhin S.K. Sovremennyj podhod k lecheniju fibroplasticheskoj induracii polovogo chlena: avtoreferat diss. dok. med. Nauk. Moskva; 2010. 36. (in Russian).

10. Tal R., Hall M.S., Alex B., Choi J., Mulhall J.P. Peyronie's disease in teenagers. J. Sex. Med. 2012; 9 (1): 302-8.

11. Smith B.H. Subclinical Peyronie's disease. Am. J. Clin. Pathol. 1969; 52 (4): 385-90.

12. Pryor J., Ralph D. Clinical presentation of Peyronies disease. Int. J .Impotence Res. 2002; 14: 414-417.

13. Mulhall J.P. Subjective and objective analysis of the prevalence of Peyronie's disease in a population of men presenting for prostate cancer screening. J. Urol. 2004; 171 (1): 2350-3.

14. Hellstrom W.J., Feldman R.A., Coyne K.S., Kaufman G.J. Self-report and Clinical Response to Peyronie's Disease Treatment: Peyronie's Disease Questionnaire Results From 2 Large Double-Blind, Randomized, Placebo-Controlled Phase 3 Studies. Urology. 2015; 86 (2): 291-98.

15. Gurzhenko Ju.N. Fibroplasticheskaja induracija polovogo chlena. Kiev; 2004. 382. (in Russian)

16. Bolezn' Pejroni. Pod red. prof. P.A. Shhepleva. M.: ID «ABV-press»; 2012. 216. (in Russian).

17. Moskaleva, Ju.S., Ostapchenko A.Ju., Korneev I.A. Bolezn Pejroni. Urologicheskie vedomosti. 2015; 4: 30-35. (in Russian).

18. Chilton C.P. Factors associated in the aetiology of Peyronie's disease. Br. J. Urol. 1982; 54 (6): 748-50.

19. Shamra€v S.M., Vozianov S.O., Gorpincheko I.I., Babjuk I.O., Nagornij O.€. Hirurgichne likuvannja deviacij statevogo organu iz zas'osuvannjam biodegradujuchogo kolagenu. Zdorov'e muzhchiny. 2009; 4: 23-26. (in Ukrainian)

20. Taruashvili I.G., Porodenko E.A., Taruashvili G.I., Simonenko E.V. Rezul'taty obsledovanija pacientov i bolezn'ju Pejroni III-IV stadiej. Kuban. nauch. med. vestn. 2005; 5-6: 115-119. (in Russian).

21. Costa W.S., Rebello S.B., Cardoso L.E., Cavalcanti A.G., Sampaio F.J. Stereological and biochemical analysis of muscular and connective tissue components in the penile corpus cavernosum adjacent to the fibrous plaque of Peyronie's disease. BJU Int. 2009; 103 (2): 212-6.

22. Paulis G, Brancato T. Inflammatory mechanisms and oxidative stress in Peyronie's disease: therapeutic «rationale» and related emerging treatment strategies. Inflamm Allergy Drug Targets. 2012; 11 (1): 48-57.

23. Anafarta K., Beduk Y., Uluoglu O., Aydos K., Baltaci S. The significance of histopathological changes of the normal tunica albuginea in Peyronie's disease. Int.Urol. Nephrol. 1994; 26: 71-77.

24. Brock G., Hsu G. The anatomy of the tunica albuginea in the normal penis and in Peyronies disease. J. Urol. (Baltimore). 1997; 157: 276-281.

25. Gelbard M.K. Dystrophic Penile calcification in Peyronie's disease. J. Urol. 1997; 157 (1): 316-319.

26. Cortés-González J.R., Glina S. Conservative treatment of Peyronie's disease: colchicine vs. colchicine plus vitamin E. Actas. Urol. Esp. 2010; 34 (5): 444-9.

27. Nejmark B.A., Besklubova E.V. Issledovanie mikrocirkuljacii $\mathrm{v}$ tkanjah polovogo chlena $\mathrm{s}$ pomoshh'ju lazernoj dopplerovskoj floumetrii pri bolezni Pejroni. Kazanskij medicinskij zhurnal. 2011; 92 (4): 513-516. (in Russian).

28. Bekos A., Arvaniti M., Hatzimouratidis K., et al. The natural history of Peyronie`s disease: an ultrasonographybased study. J. Urol. 2008; 53 (3): 644-650.

29. Kovac J.R., Brock G.B. Surgical outcomes and patient satisfaction after dermal, pericardial, and small intestinal submucosal grafting for Peyronie`s disease. J. Sex. Med. 2007; 4: 1500-1508.

30. Ralph D.J., Schwartz G., Moore W., Pryor J.P., Ebringer A., Bottazzo G.F. The genetic and bacteriological aspects of Peyronie's disease. J. Urol. 1997; 157 (1): 291-4.

31. El-Sakka A.I., Salabas E., Dinçer M., et al. The pathophys- 
Urology. 2013; 11: 272-277.

32. Bivalacqua T.J., Champion H.C., Leungwattanakij S. et al. Evaluation of nitric oxide synthase and arginase in the induction of a Peyronie's. Journal of Andrology. 2001; 22: 497-506.

33. Gonzalez-Cadavid NF. Mechanisms of penile fibrosis. J. Sex. Med. 2009; 6 (3): 353-62.

34. Cantini L.P., Ferrini M.G., Vernet D. et al. Profibrotic role of myostatin in Peyronie's disease. Journal of Sexual Medicine. 2008; 5: 1607-22

35. Gonzalez-Cadavid NF. Mechanisms of penile fibrosis. J. Sex. Med. 2009; 6 (3): 353-62.

36. Byström J, Rubio C. Induratio penis plastica Peyronie's disease. Clinical features and etiology. Scand. J. Urol. Nephrol. 1976; 10 (1): 12-20.

37. Karavitakis M., Komninos C., Simaioforidis V., Kontos S. The relationship between androgens, regulators of collagen metabolism, and Peyronie's disease: a case control study. J. Sex. Med. 2010; 7 (12): 4011-7.

38. Jalkut M., Gonzalez-Cadavid N., Rajfer J. New discoveries in the basic science understanding of Peyronie's disease. Curr. Urol. Rep. 2004; 5 (6): 478-84.

39. Perovic S.V., Dinovic R.P. Current surgical management of severe Peyronie's disease. Arch. Esp. Urol. 2010; 63 (9): 755-70.

40. Возианов С.А., Шамраев С.Н., Ермилов С.Г, Шлопов В.Г. Новый взгляд на пато- и морфогенез идиопатической фибропластической индурации полового члена (болезни Пейрони). Здоровье мужчины. 2012; 2 (41): $11-15$. iology of Peyronie's disease. Arab Journal of Urology. 2013; 11: 272-277.

32. Bivalacqua T.J., Champion H.C., Leungwattanakij S. et al. Evaluation of nitric oxide synthase and arginase in the induction of a Peyronie's. Journal of Andrology. 2001; 22: 497-506.

33. Gonzalez-Cadavid NF. Mechanisms of penile fibrosis. J. Sex. Med. 2009; 6 (3): 353-62.

34. Cantini L.P., Ferrini M.G., Vernet D. et al. Profibrotic role of myostatin in Peyronie's disease. Journal of Sexual Medicine. 2008; 5: 1607-22

35. Gonzalez-Cadavid NF. Mechanisms of penile fibrosis. J. Sex. Med. 2009; 6 (3): 353-62.

36. Byström J, Rubio C. Induratio penis plastica Peyronie's disease. Clinical features and etiology. Scand. J. Urol. Nephrol. 1976; 10 (1): 12-20.

37. Karavitakis M., Komninos C., Simaioforidis V., Kontos S. The relationship between androgens, regulators of collagen metabolism, and Peyronie's disease: a case control study. J. Sex. Med. 2010; 7 (12): 4011-7.

38. Jalkut M., Gonzalez-Cadavid N., Rajfer J. New discoveries in the basic science understanding of Peyronie's disease. Curr. Urol. Rep. 2004; 5 (6): 478-84.

39. Perovic S.V., Djinovic R.P. Current surgical management of severe Peyronie's disease. Arch. Esp. Urol. 2010; 63 (9): 755-70.

40. Vozianov S.A., Shamraev S.N., Ermilov S.G, Shlopov V.G. Novyj vzgljad na pato-i morfogenez idiopaticheskoj fibroplasticheskoj induracii polovogo chlena (bolezni Pejroni). Zdorov'e muzhchiny. 2012; 2 (41): 11-15. (in Russian). 